\title{
Transplantation of allogenic nucleus pulposus cells attenuates intervertebral disc degeneration by inhibiting apoptosis and increasing migration
}

\author{
WEIHENG WANG $^{1 *}$, GUOYING DENG ${ }^{2 *}$, YUANYUAN QIU ${ }^{3 *}$, XIAODONG HUANG ${ }^{1}$, \\ YANHAI XI ${ }^{1}$, JIANGMING YU $^{1}$, XIANGQUN YANG $^{4}$ and XIAOJIAN YE ${ }^{1}$ \\ ${ }^{1}$ Department of Orthopaedics, Changzheng Hospital, Second Military Medical University, Shanghai 200003; \\ ${ }^{2}$ Trauma Center, Shanghai General Hospital, School of Medicine, Shanghai Jiaotong University, Shanghai 201620; \\ ${ }^{3}$ Department of Respiratory Medicine, The Electric Power Hospital, Shanghai 200050; \\ ${ }^{4}$ Department of Anatomy, Institute of Biomedical Engineering, \\ Second Military Medical University, \\ Shanghai 200433, P.R. China
}

Received September 1, 2017; Accepted January 24, 2018

DOI: $10.3892 /$ ijmm.2018.3454

\begin{abstract}
Transplantation of nucleus pulposus cells (NPCs) into the intervertebral disc (IVD) has been demonstrated to be an effective treatment of degenerative disc disease (DDD). However, the underlying mechanisms have remained to be sufficiently elucidated. The aim of the present study was to explore the potential cell migration and anti-apoptosis efficacy of NPCs in the treatment of DDD. NPCs cultured from rats expressing green fluorescent protein (GFP-NPCs) were transplanted into the degenerated IVD, and the migration of GFP-NPCs, as well as the degeneration and apoptosis of the IVD were detected to evaluate the therapeutic effect in vivo. In vitro, disc chondrocytes (DCs) and annulus fibrosus cells (AFCs) were co-cultured to explore the underlying mechanism. The results demonstrated that injection of NPCs suppressed DDD by inhibiting apoptosis and increasing extracellular matrix in vivo and in vitro. NPCs migrated into the inner AF in vivo, and NPC migration was observed to be promoted by AFCs and DCs in vitro, particularly by damaged AFCs. These results demonstrated the anti-apoptotic effects and migratory
\end{abstract}

Correspondence to: Dr Xiangqun Yang, Department of Anatomy, Institute of Biomedical Engineering, Second Military Medical University, 800 Xiangyin Road, Shanghai 200433, P.R. China

E-mail: yangxq_sh@126.com

Dr Xiaojian Ye, Department of Orthopaedics, Changzheng Hospital, Second Military Medical University, 415 Fengyang Road, Shanghai 200003, P.R. China

E-mail: xjyespine@smmu.edu.cn

*Contributed equally

Key words: nucleus pulposus cells, cell therapy, degenerative disc disease, apoptosis, migration capacity of allogenic NPCs transplanted into the IVD, which evidences the contribution of NPCs to disc regeneration and provide a novel strategy for treating DDD.

\section{Introduction}

Chronic back and neck pain caused by intervertebral disc (IVD) degeneration continues to be a severe health problem. IVD degeneration is a relentlessly progressive phenomenon with no effective treatment currently available (1), and is a common cause of the loss of disability-adjusted life years worldwide (2). Degenerative disc disease (DDD) is typically managed by surgical interventions, including lumbar or cervical interbody fusion. Although surgery may alleviate clinical symptoms, it is unable to arrest the progression of degeneration or restore the native functional state of the IVD. In addition, procedure-associated complications, including adjacent segment disease, often require further surgical procedures $(3,4)$. An alternative strategy to treat DDD is urgently required.

The IVD is the largest avascular human organ, and disc degeneration naturally occurs with age and circumstances secondary to various spinal disorders (5). A number of factors contribute to IVD degeneration, although the precise molecular mechanisms remain to be elucidated. DDD is clinically characterized by a loss of the disc height, proper stability and mobility. Histologically, disc degeneration is characterized by a loss of nucleus pulposus cells (NPCs), and their replacement by cells of a more fibroblast-like phenotype and decreased extracellular matrix (ECM) products, including aggrecan and collagen II, produced by NPCs $(6,7)$. Due to the regeneration of NPCs, annulus fibrosus cells (AFCs) and disc chondrocytes (DCs) being limited in vivo, reconstructing the ECM may be an effective strategy to treat DDD. Cells, including freshly cryopreserved NP (8), stimulate NPCs (9), bone marrow mesenchymal stem cells $(10,11)$ and olfactory stem cells $(12)$, and have been studied for years as a potential treatment of 
DDD, demonstrating promising effects of self-renewal of cells and the production and secretion of ECM (13). NPC transplantation is one strategy to prevent IVD degeneration $(14,15)$. There are limited studies on the underlying mechanisms of actions of NPCs to repair DDD, and no studies, to the best of our knowledge, on the migration of transplanted NPCs in IVD.

The aim of the present study was to explore the effect of NPCs in the treatment of DDD and underlying mechanisms. Animal experiments were designed to detect the migration of green fluorescent protein (GFP)-labeled NPCs, and the degeneration and apoptosis of IVDs in vivo. To explore the migratory capacity and anti-apoptosis efficacy of NPCs as well as the potential molecular mechanisms, NPCs of were cultured with AFCs and DCs in vitro, and apoptosis as well as ECM-associated genes and proteins were detected.

\section{Materials and methods}

Animals and establishment of the DDD model. A total of 30 Sprague Dawley (SD) and 10 green fluorescent protein (GFP) transgenic SD rats (male; age, 3 months; skeletal maturity at this age) were purchased from the Shanghai Lingchang BioTech Co., Ltd. (Shanghai, China). The rats were housed for one week under controlled conditions (12-h light/dark cycle; temperature, $22-24^{\circ} \mathrm{C}, 50-60 \%$ relative humidity) with free access to food and water prior to initiation of the experiment. All procedures were approved by the Institutional Animal Care and Use Committee of the Second Military Medical University (Shanghai, China). A DDD model was established as described by Hughes and Tanner (16). A longitudinal incision of $\sim 2 \mathrm{~cm}$ was made along the tail to expose the lateral portion of the tail disc Co6/Co7 and Co7/Co8, and a 21-g needle was inserted at a depth of $1.5 \mathrm{~mm}$ into the disc (excluding the depth of the skin) following anesthesia by intraperitoneal injection of pentobarbital sodium (50 mg/kg, intraperitoneal injection). Radiographic images were captured to ensure that the needle was parallel to endplates to avoid endplate damage (Fig. 1A). The needle was then removed and the tail skin was closed using separated stitches.

Isolation and identification of NPCs, AFCs and DCs. Rats were sacrificed with an overdose of pentobarbital sodium (100 mg/kg, intraperitoneal injection) and the NPCs, AFCs and DCs were prepared as previously described $(15,17,18)$. The cells used in this experiment were at the third passage (P3). The cells type and purity were identified by immunofluorescence staining for collagen-II and aggrecan. The cells were blocked with 5\% donkey serum (Beijing Solarbio Science \& Technology Co., Ltd., Beijing, China) for $30 \mathrm{~min}$ at room temperature and incubated overnight with rabbit anti-rat collagen II (1:200; cat. no. ab188570; Abcam, Cambridge, MA, USA) and rabbit anti-rat aggrecan (1:200, cat. no. 13880-1-AP, ProteinTech Group, Inc., Chicago, IL, USA) primary antibodies at $4^{\circ} \mathrm{C}$. Subsequently, following an incubation with goat anti-rat secondary antibody (1:500, cat. no. M21003, Abmart, Inc., Shanghai, China) for $2 \mathrm{~h}$ at room temperature, nuclei were stained DAPI. The observation was carried out with a fluorescence microscope (Olympus Corp., Tokyo, Japan). Transplanted NPCs expressing GFP (GFP-NPCs) were isolated from GFP transgenic SD rats and used to identify the location of the transplanted cells.

Experimental design of in vivo study. A total of 30 rats were randomized into 3 groups: Sham group, model group and NPC group $(n=10)$. In the Sham group, the tail disc was exposed without inserting a needle, while the rats in the model and NPC groups were treated by needle insertion. After 2 weeks, $2.0 \mu \mathrm{l}$ PBS (0.01 M) in the model group, and P3 GFP-NPCs $\left(2 \times 10^{4}\right)$ suspended in $2.0 \mu \mathrm{l}$ PBS in the NPC group were injected into $\mathrm{Co6} / \mathrm{Co} 7$ and $\mathrm{Co} / \mathrm{Co} 8$ discs through a 33-g microinjector (Hamilton Bonaduz AG, Bonaduz, Switzerland) for at least 5 min to prevent liquid leakage. At 4 weeks following GFP-NPC transplantation, IVDs of $\mathrm{Co6} / \mathrm{Co} 7$ and $\mathrm{Co} 7 / \mathrm{Co} 8$ were obtained for analysis.

Radiographic analysis. At week 0, 2, 4 and 6 following surgery, lateral plain radiographs were obtained following anesthesia by pentobarbital sodium ( $50 \mathrm{mg} / \mathrm{kg}$, intraperitoneal injection) to keep the caudal muscle relaxed. The disc height index (DHI) was calculated as described by Lin et al (19). All images were quantitatively evaluated by three independent observers blinded to the specimens. Changes in DHI were expressed as $\%$ DHI and normalized to the measured preoperative IVD height $(\% \mathrm{DHI}=$ postoperative $\mathrm{DHI} /$ preoperative $\mathrm{DHI} \times 100$, $\mathrm{n}=10$ ). Changes of DHI were analyzed by ImageJ 1.45 software (National Institutes of Health, Bethesda, MD, USA).

Histological analysis. At week 4 following cell transplantation, the rats were sacrificed by an overdose of pentobarbital. $\mathrm{Co6} / \mathrm{Co} 7$ and $\mathrm{Co} 7 / \mathrm{Co} 8$ discs were harvested, fixed, soaked and decalcified. Subsequently, $5-\mu \mathrm{m}$ sections were stained with hematoxylin for $5 \mathrm{~min}$ and eosin for $3 \mathrm{~min}$ at room temperature $(\mathrm{H} \& \mathrm{E})$. Histological grading was used for evaluating the degenerative changes according to Pfirrmann et al (20). Histological scoring was performed by two independent observers for inter-observer reliability, and 5 transects were randomly selected for cell counting $(n=5)$.

Evaluation of migration and proliferation of NPCs in vivo. At week 4 following GFP-NPC transplantation, Co7/Co8 discs were harvested and processed individually in Tissue Tek optimal cutting temperature compound (Sakura Finetek USA, Inc., Torrance, CA, USA). Discs were sectioned by a cryotome (CM 1950; Leica Microsystems GmbH, Wetzlar, Germany) in the coronal direction to obtain $7-\mu$ m-thick sections. The sections were stained with DAPI. Transplanted NPCs-GFP with spontaneous green fluorescence were detected and observed under a fluorescence microscope (Olympus Corp.). The observation was performed and cells were counted in 5 randomly selected fields of vison/group (magnification, $\mathrm{x} 200 ; \mathrm{n}=5$ ).

Generation of a cell damage model. P3 DCs and AFCs were induced by interleukin (IL)-1 $\beta$ (20 ng/ml) in Dulbecco's modified Eagle's medium (DMEM)-F12 (HyClone; GE Healthcare Life Sciences, Logan, UT, USA) without fetal bovine serum (FBS) for $24 \mathrm{~h}$ to generate a cell damage model and the cells were co-cultured with NPCs in a Transwell induction assay (pore width, 0.4 $\mu \mathrm{m}$; EMD Millipore, Billerica, MA, USA) (21). 
Table I. Sequences of primers used for polymerase chain reaction.

\begin{tabular}{lll}
\hline Gene & \multicolumn{1}{c}{ Forward primer (5'-3') } & \multicolumn{1}{c}{ Reverse primer (5'-3') } \\
\hline GAPDH & GCAAGTTCAACGGCACAG & GGCCCCTCCTGTTGTTATGG \\
Collagen II & GTTCACGTACACTGCCCTGA & AAGGCGTGAGGTCTTCTGTG \\
Aggrecan & GAAGTGGCGTCCAAACCAAC & AGCTGGTAATTGCAGGGGAC \\
MMP-13 & TGCTGCATACGAGCATCCAT & TTCCCCGTGTCCTCAAAGTG \\
TIMP-1 & TACCAGCGTTATGAGATCAAGATGAC & CCATGAGGATCTGATCTGTCCACA \\
Caspase-3 & GCGGTATTGAGACAGACAGTGGAAC & GCGGTAGAGTAAGCATACAGGAAGT
\end{tabular}

TIMP, tissue inhibitor of MMPs; MMP, matrix metalloproteinase.

The following groups were established: Blank group, Control group and Experimental group. In the Blank group, $5 \times 10^{4}$ P3 DCs or AFCs were cultured in DMEM-F12 without FBS for $24 \mathrm{~h}$, and the medium was replaced by DMEM-F12 with 10\% FBS (Gibco; Thermo Fisher Scientific, Inc., Waltham, MA, USA) without NPCs in the inner Transwell. In the Control and Experimental groups, $5 \times 10^{4}$ DCs or AFCs were induced with IL-1 $\beta(20 \mathrm{ng} / \mathrm{ml})$ in DMEM-F12 without FBS for $24 \mathrm{~h}$. Subsequently, Transwells containing 0 or $5 \times 10^{4}$ NPCs co-cultured with DCs or AFCs, respectively, were incubated with $10 \%$ FBS in DMEM-F12 for $24 \mathrm{~h}$. DCs and AFCs were digested with $0.25 \%$ trypsin (pre-warmed to $37^{\circ} \mathrm{C}$; Gibco; Thermo Fisher Scientific, Inc.) at $37^{\circ} \mathrm{C}$ for $2-3 \mathrm{~min}$ and DMEM-F12 with $10 \%$ FBS was added to terminate digestion. Following sufficient pipetting to dissociate the cells, cells in suspension were centrifuged at $150 \mathrm{x} \mathrm{g}$ for $5 \mathrm{~min}$ at $20^{\circ} \mathrm{C}$ and the supernatant was discarded. The harvested cells were analyzed by flow cytometry (FAC500; Beckman Coulter, Inc., Brea, CA, USA) according to the manufacturer's protocols. Flow cytometric analysis was performed by BD FACSDiva software (version 6.1.3; BD Biosciences, Franklin Lakes, NJ, USA). A total of 5 samples were randomly selected from each of the three groups and stained with an Annexin V and propidium iodide kit (BD Biosciences). All samples were detected within $1 \mathrm{~h}$ following staining ( $\mathrm{n}=5)$.

Migration assay. The P3 DCs and AFCs were induced by IL-1 $\beta(20 \mathrm{ng} / \mathrm{ml})$ in DMEM-F12 without FBS for $24 \mathrm{~h}$ to generate a cell damage model and co-cultured with NPCs in a Transwell induction assay ( $8 \mu \mathrm{m}$ pore width; EMD Millipore) to study cell migration in vitro. The following groups were established: Blank group, Control group and Experimental group. In the Blank group, $5 \times 10^{4}$ NPCs were seeded and cultured in inner Transwell without AFCs or DCs in the bottom well for $12 \mathrm{~h}$. In the Control group, $5 \times 10^{4} \mathrm{DCs}$ or AFCs were cultured in DMEM-F12 without FBS for $24 \mathrm{~h}$, and $5 \times 10^{4}$ NPCs in the Transwell insert were then co-cultured with these DCs or AFCs for $12 \mathrm{~h}$. In the Experimental group, $5 \times 10^{4} \mathrm{DCs}$ or AFCs were induced by IL-1 $\beta(20 \mathrm{ng} / \mathrm{ml})$ in F-12 without FBS for $24 \mathrm{~h}$, and $5 \times 10^{4}$ NPCs in the Transwell insert were then co-cultured with these DCs and AFCs for $12 \mathrm{~h}$. Following $12 \mathrm{~h}$ of co-culture, the Transwell chamber was dried at room temperature, and NPCs were stained with $0.1 \%$ crystal violet for $20 \mathrm{~min}$ at room temperature. The non-migrated cells in the upper layer were gently wiped off with a cotton swab. The images were captured with a microscope (Olympus Corp.). A total of 5 transects were randomly selected for cell counting $(\mathrm{n}=5$; Olympus Corp.).

Semi-quantitative reverse transcription polymerase chain reaction (RT-PCR). The mRNA expression of collagen II, aggrecan, matrix metalloproteinase (MMP)-13 and tissue inhibitor of MMPs (TIMP)-1 in endplate cartilage tissue, AFCs and DCs was detected by RT-PCR. Total mRNA was extracted using isogen reagent in accordance with the manufacturer's protocols (Nippon Gene, Co., Ltd., Tokyo, Japan). A total of $1 \mu \mathrm{g}$ total RNA samples were reverse transcribed to cDNA using a RT kit (Generay Biotech Co., Ltd., Shanghai, China) in a $20 \mu \mathrm{l}$ volume according to the following temperature protocol: $37^{\circ} \mathrm{C}$ for $15 \mathrm{~min}, 85^{\circ} \mathrm{C}$ for $5 \mathrm{sec}$, followed by $5 \mathrm{~min}$ at $4^{\circ} \mathrm{C}$. PCR was conducted using Maxima ${ }^{\mathrm{TM}}$ SYBR-Green/ROX qPCR Master Mix (Thermo Fisher Scientific, Inc.) according to the instructions provided by the manufacturer using the Stratagene mx3000P real-time PCR system (Agilent Technologies, Inc., Santa Clara, CA, USA). The thermocycling conditions were: $95^{\circ} \mathrm{C}$ for $5 \mathrm{~min} ; 40$ cycles of $95^{\circ} \mathrm{C}$ for $10 \mathrm{sec}$ and $60^{\circ} \mathrm{C}$ for $34 \mathrm{sec}$. PCR products were separated on a $1.2 \%$ agarose gel (with ethidium bromide staining). The resultant gel image was analyzed using the AlphaImager gel analysis system (AlphaImager 2000; ProteinSimple, San Jose, CA, USA). The mRNA expression of target genes was calculated using the method $2^{-\Delta \Delta c t}$ and normalized to that of GAPDH $(n=5)$ (22). The primers were synthesized by Shenggong Biomedical Engineering (Shanghai, China; Table I).

Western blot analysis. The protein expression of collagen II, aggrecan, MMP-13 and TIMP-1 in endplate cartilage tissue, AFCs and DCs was detected by western blot analysis. The cells were lysed in cell lysis buffer (Intron Biotechnology, Inc., Seongnam, Korea) for $20 \mathrm{~min}$ on ice. The lysed cells were centrifuged at $12,000 \mathrm{xg}$ for $10 \mathrm{~min}$ at $4^{\circ} \mathrm{C}$ and the supernatant was collected. The proteins were extracted from the intestinal mucosa using the above lysis buffer, followed by homogenization through sonication $\left(130 \mathrm{~W}, 20 \mathrm{KHz}, 4^{\circ} \mathrm{C}, 5 \mathrm{sec}, 10\right.$ cycles $)$ and the extraction mixture was centrifuged at $12,000 \mathrm{x}$ g for $15 \mathrm{~min}$ at $4^{\circ} \mathrm{C}$. The total protein content in each sample was determined by the bicinchoninic acid method. Protein samples $(25 \mu \mathrm{g})$ were separated by $10 \%$ SDS-PAGE and the proteins were 
transferred to polyvinylidene fluoride membranes (Amersham; GE Healthcare, Chicago, IL, USA). The membranes were blocked in TBS containing 0.05\% Tween-20 (TBS-T) and 5\% bovine serum albumin (BSA; Sigma-Aldrich; Merck KGaA) for $2 \mathrm{~h}$ at $37^{\circ} \mathrm{C}$. Then membrane was probed with antibodies for rabbit anti-rat collagen II (1:2,000; cat. no. ab188570; Abcam), rabbit anti-rat aggrecan (1:1,000; cat. no. 13880-1-AP; ProteinTech Group, Inc.), mouse anti-rat TIMP-1 antibody (1:1,000; cat. no. MAB3300; EMD Millipore), rabbit anti-rat MMP-13 (1:3,000; cat. no. ab39012; Abcam) and rabbit anti-rat caspase-3 (cat. no. 9662; Cell Signaling Technology, Inc., Danvers, MA, USA) at $4^{\circ} \mathrm{C}$ for $12 \mathrm{~h}$. Following incubation with anti-rabbit and anti-mouse horseradish peroxidase-conjugated secondary antibody at $4^{\circ} \mathrm{C}(1: 15,000$; cat. nos. M21003 and M21001; Abmart) for $45 \mathrm{~min}$ and washed again prior to detection of signal with Western Lighting Plus-ECL reagents (cat. no. P1010; Applygen Technologies, Inc., Beijing, China). The protein levels were quantified using densitometry analysis with Sigma Scan Pro 5 (Systat Software Inc., San Jose, CA, USA) and normalized to the levels of GAPDH.

Statistical analysis. SPSS software was used for data analysis (version 21.0; IBM Corp., Armonk, NY, USA). Statistical analysis was conducted using Student's t-test for comparing two groups of data and one-way analysis of variance with Bonferroni post hoc test for multiple comparisons. The results of the histological scores were analyzed using the Kruskal-Wallis test. $\mathrm{P}<0.05$ was considered to indicate a statistically significant difference. Values are expressed as the mean \pm standard deviation.

\section{Results}

Isolation and identification of NPCs, DCs and AFCs. Typical primary NPCs were round or polygonal with projections, whereas P3 NPCs were polygonal and single-cell shaped with large and complete nuclei (Fig. 1A). The newly isolated DCs demonstrated a spherical shape with strong refraction, and P3 DCs were polygonal with single-cell morphology (Fig. 1B). In the primary culture, AFCs were polygonal or spindle-shaped, and the typical P3 cells were spindle-shaped with numerous projections (Fig. 1C). Immunofluorescence staining of collagen II and aggrecan demonstrated that NPCs, DCs and AFCs were markedly positive, indicating that the cultured cells were NPCs, DCs and AFCs. Fluorescence microscopy demonstrated that all GFP-NPCs were labeled with GFP (Fig. 1D). All data indicated that the obtained cells were of high purity and suitable for subsequent tests.

Assessment of disk degeneration. Radiography demonstrated no significant change of DHI in the Sham group, while DHI gradually was decreased at week 2 following DDD modeling in the model and NPC groups (Fig. 2). The mean DHI in the model group continued to decrease until week 6 following the induction of IVD degeneration. The mean DHI in the model group was $100 \%$ in the beginning of the study vs. $89.3 \pm 3.8$, $83.1 \pm 3.8$ and $78.6 \pm 3.9 \%$ at weeks 2,4 and 6 , respectively; in the NPC group, the DHI was $89.5 \pm 3.1,87.3 \pm 4.2$ and $88.3 \pm 3.6 \%$ at weeks 2, 4 and 6, respectively. The DHI in the NPC group at week 4 following transplantation was higher than that in the
Model group $(n=10 ; \mathrm{P}<0.05)$, suggesting that NPC transplantation partially restored the disc height.

Histological analysis. To study the degeneration of IVDs, histological analysis was performed to determine IVD changes at week 4 following NPC transplantation. H\&E staining demonstrated morphological changes in the NP and AF regions. Histological analysis confirmed the regenerative effect of the procedure. NPCs in the Sham group demonstrated oval-shaped nuclei with no collapse of inner annular structure, and only one disc in the Sham group demonstrated the serpentine appearance of an AF with rupture (Fig. 3A). Cell morphological analysis demonstrated the loss of the well-distributed pattern in the model group, and the cell number in the NP was gradually reduced, with clustering in certain areas. The inner annulus morphology began to collapse, and fibroblast-like cell invasion was initiated from the surrounding region. Beginning from the surrounding region, fibrosis was observed in the nucleus (Fig. 3B). The discs in the NPC group demonstrated a relatively well-preserved inner annulus structure with minimal fibrosis (Fig. 3C). According to histological scoring by H\&E staining, the discs in the NPC group were graded as 2-3 at week 4 following NPC transplantation vs. $4-5$ in the model, and discs in Sham group remained unchanged at 0 (Fig. 3D). Compared with those in the Sham group, the degeneration scores in the model and NPC groups were significantly increased, and significantly decreased in the NPC group compared with those in the model group (Fig. 3D; $\mathrm{P}<0.05$ ). These results demonstrated that NPC transplantation partially restored the DDD-associated changes in disc structure.

Evaluation of NPC survival and migration. GFP-positive cells were detected in the NP region of the sections obtained at week 4 following transplantation in the majority of NPC-transplanted rat IVDs (Fig. 4). None of the discs in the Sham and Model groups contained any GFP-positive cells (data not shown). GFP-NPCs spontaneously fluoresced under fluorescence microscopy, and their proliferation had little effect on their fluorescence intensity. The majority of the GFP-NPCs were distributed in the NP region and localized in the transition zone. In 3 of the 5 discs, GFP-positive cells were localized in the inner AF region. These GFP-positive cells in the inner AF were spindle-shaped, similar to native AFCs and different from the GFP-NPCs in the NP region (Fig. 4B, red straight line separated the two regions). The GFP-NPCs localized in the transition zone presented a more rounded shape, similar to native NPCs (Fig. 4A). These results demonstrated that transplanted GFP-NPCs had survived in intervertebral discs at week 4 following transplantation and mainly localized in the transition zone, and that a number of GFP-NPCs were able to migrate into the inner $\mathrm{AF}$ region.

$N P C s$ regulate the $m R N A$ and protein expression of the ECM-associated genes collagen II, aggrecan, MMP-13 and TIMP-1. Western blotting and semi-quantitative RT-PCR were used to analyze changes of collagen II, aggrecan, MMP-13 and TIMP-1 expression in endplate cartilage tissue harvested at week 4 following cell transplantation (Fig. 5). The mRNA and protein expression of collagen II and aggrecan was significantly decreased in the model and NP groups compared 


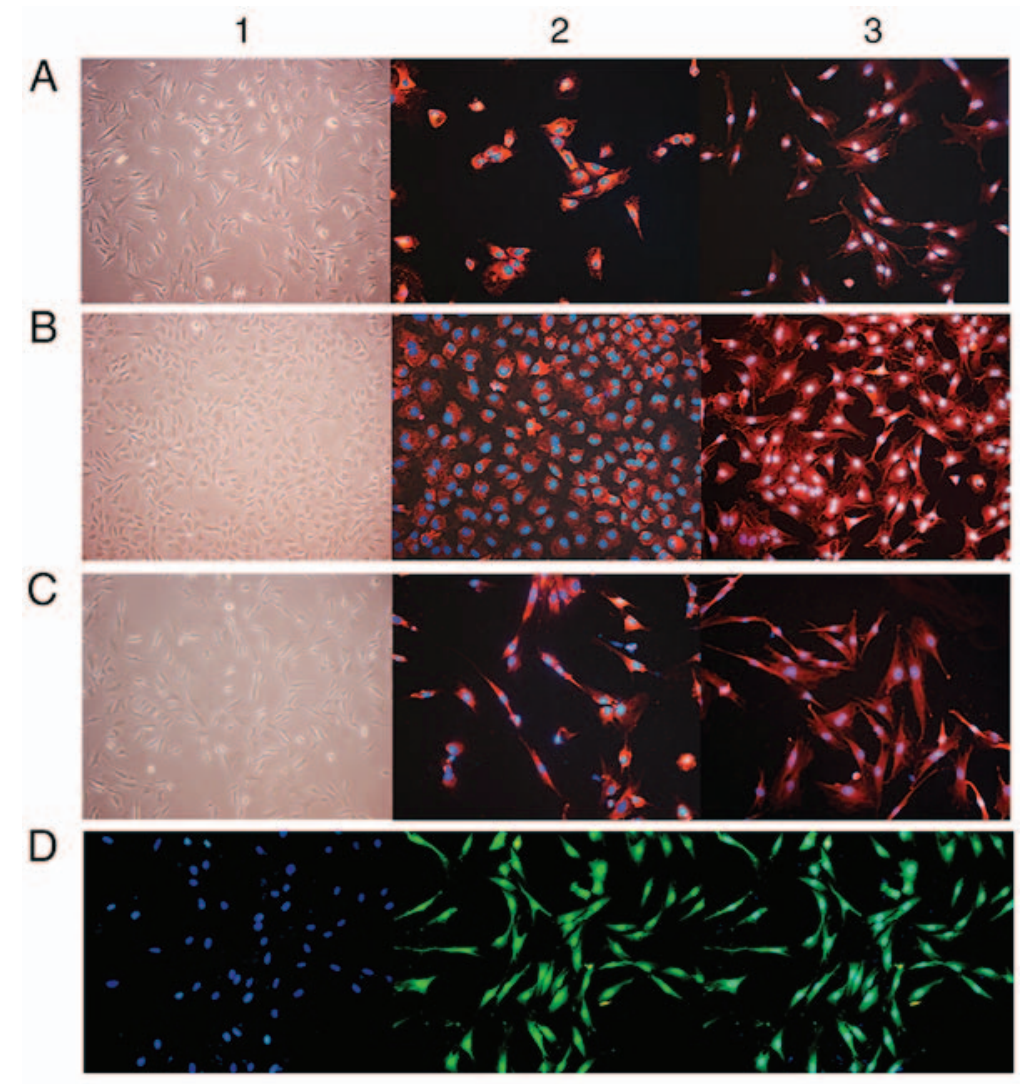

Figure 1. Morphology and identification of (A) NPCs, (B) DCs and (C) AFCs. Panel displays phase contrast images, and panels 2 and 3 display red immunofluorescence staining of collagen II and aggrecan, respectively (magnification, x400). (D) GFP-NPCs with channels displaying DAPI (nuclei stained in blue) in panel 1, GFP is green in panel 2 and a merged image in panel 3 (magnification, x400). NPCs, nucleus pulposus cells; DCs, chondrocytes; AFCs, annulus fibrosus cells; GFP, green fluorescent protein.

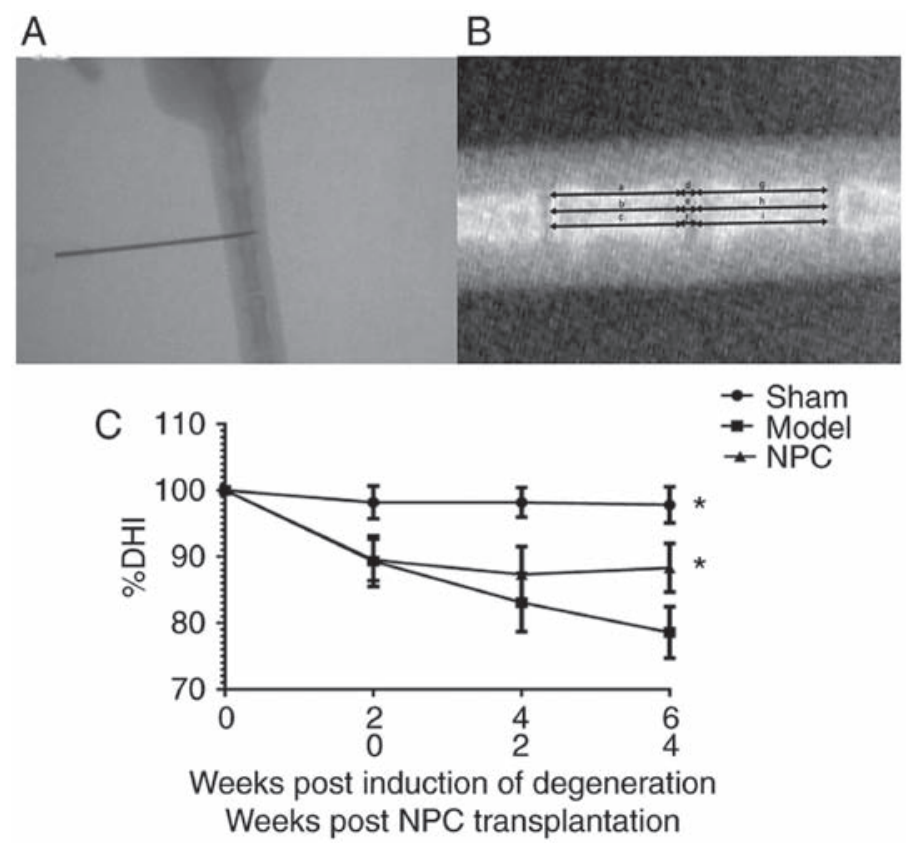

Figure 2. Assessment of disc degeneration. (A) Representative lateral radiography image of the needle-induced disc degeneration process in the animal model. (B) Measurement protocol for the determination of the DHI calculated as [2 magnification $x(d+e+f) /(a+b+c+g+h+i) \times 100 \%]$. (C) DHI at different time-points following NPC transplantation. Values are expressed as the mean \pm standard deviation $(n=10)$. ${ }^{*} \mathrm{P}<0.05$ vs. Model group. DHI, disc height index; NPC, nucleus pulposus cell.

with that in the Sham group $(\mathrm{P}<0.01)$, indicating that DDD is associated with a marked decrease in the expression of collagen II and aggrecan. In addition, the mRNA and protein expression levels of collagen II and aggrecan in the NPC 


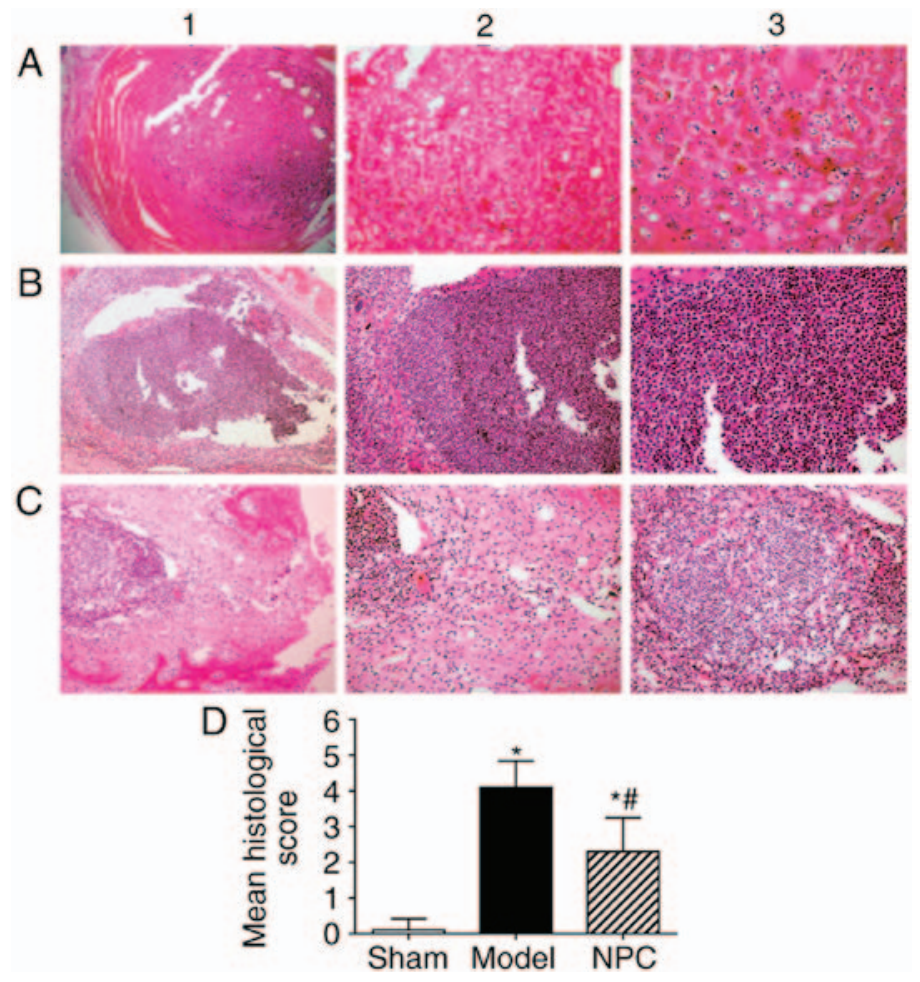

Figure 3. Histological changes at week 4 following NPC transplantation. (A) Discs in the Sham group exhibited intact nucleus pulposus and annulus fibrosus cells, and distributed stellar nucleus cells with large vacuoles within the nucleus pulposus. (B) Discs in the model group displayed a collapse of the inner annulus morphology and fibrotic changes in the nuclei due to cell invasion from the surrounding region. (C) The discs in the NPC group had a relatively preserved inner annulus structure with minimal fibrosis in the nuclear region (magnification, x100, x200 and x400 in panels 1, 2 and 3, respectively). (D) Histological grading scores at week 4 following NPC transplantation. Values are expressed as the mean \pm standard deviation $(\mathrm{n}=5)$. ${ }^{*} \mathrm{P}<0.05$ vs. Sham group; ${ }^{*} \mathrm{P}<0.05$ vs. model group. NPC, nucleus pulposus cell.
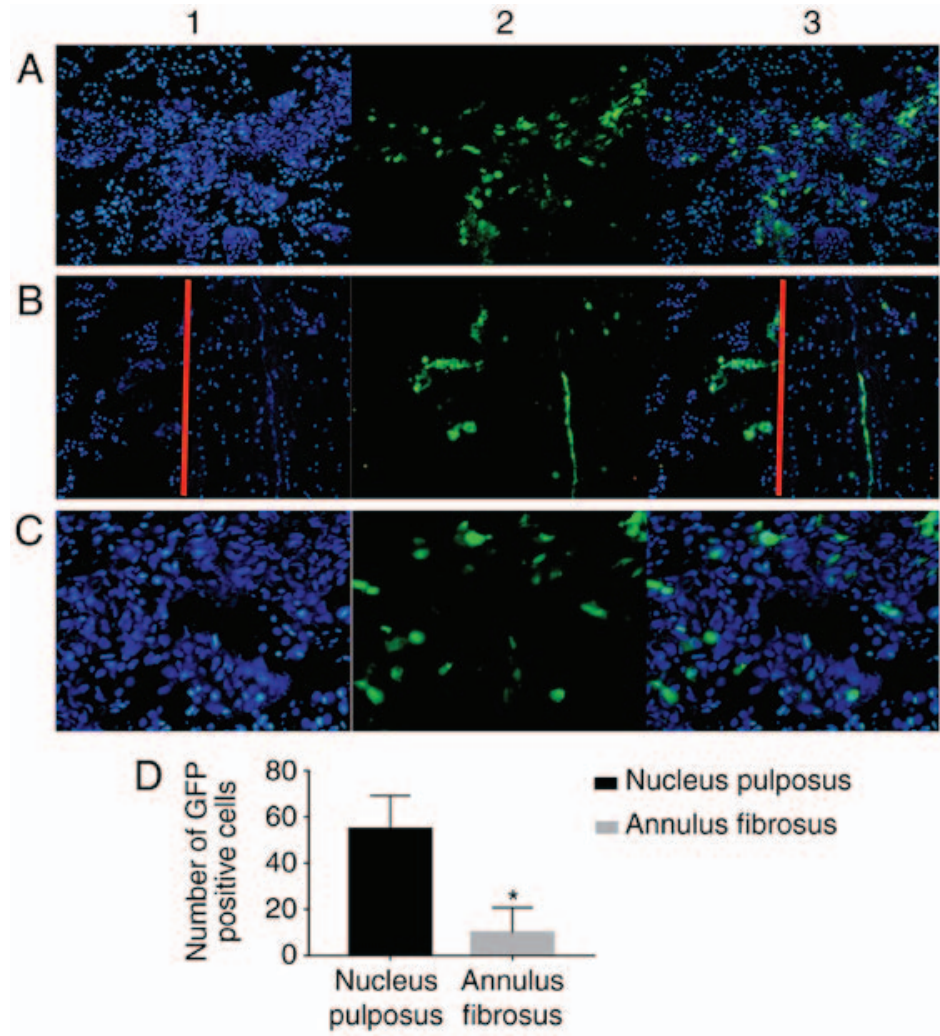

Figure 4. Evaluation of NPC survival and migration in discs at week 4 following transplantation. Fluorescence microscopy images at magnifications of (A) $x 200$; (B) $\times 200$ (C) x400. The red straight line separates the nucleus pulposus region and inner annulus fibrosus region. Panel 1 displays DAPI staining of nuclei, panel 2 displays GFP and panel 3 displays merged images. (D) The number of GFP-positive cells in the nucleus pulposus region and inner annulus fibrosus region. Values are expressed as the mean \pm standard deviation $(n=5)$. ${ }^{*} \mathrm{P}<0.05$ vs. the nucleus pulposus region. NPC, nucleus pulposus cell; GFP, green fluorescent protein. 

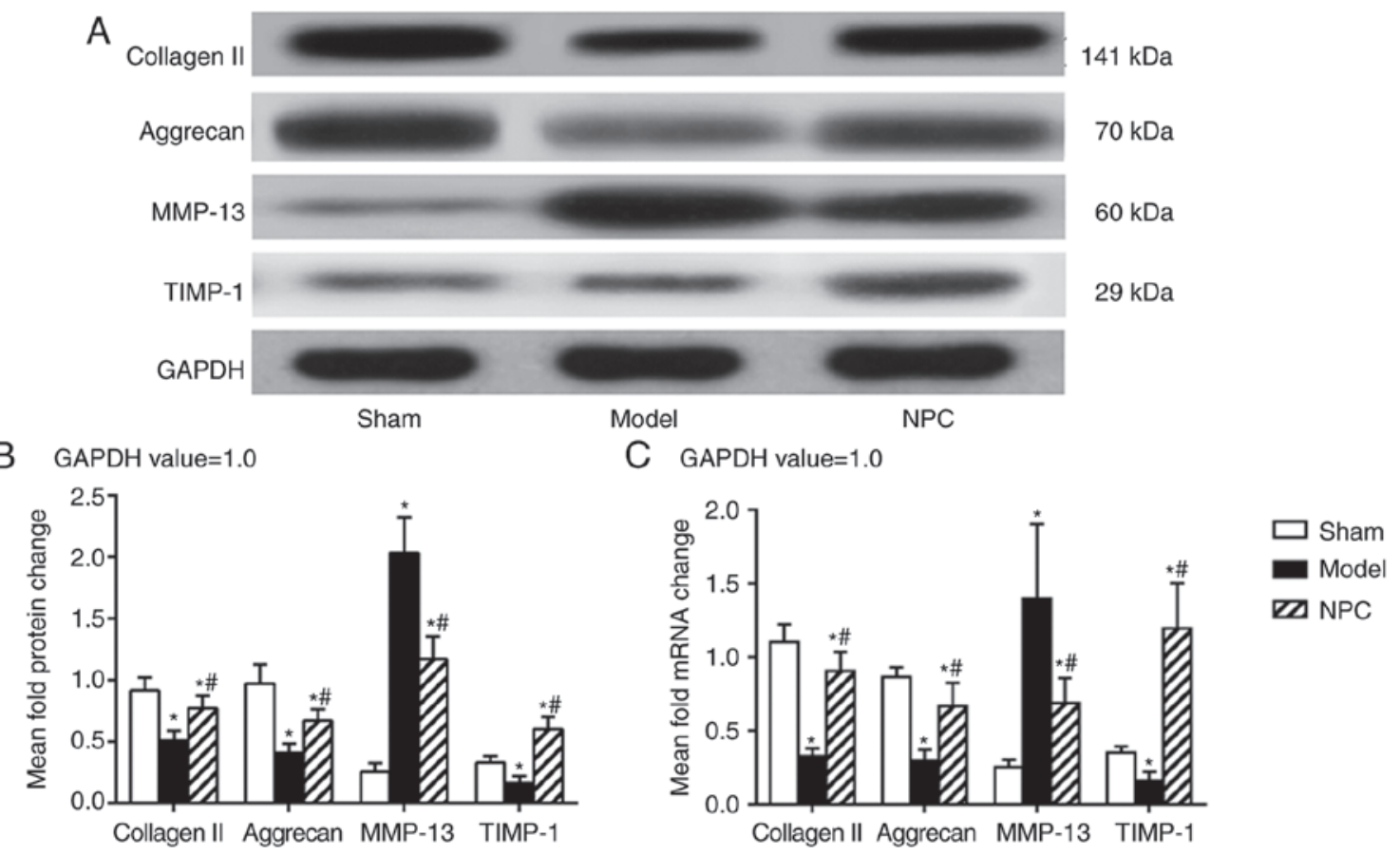

Figure 5. Effect of NPCs on ECM-associated mRNA and protein expression (n=6). (A and B) Western blot analysis of collagen II (141 kDA), aggrecan, MMP-13 and TIMP-1 protein expression in endplate cartilage tissue. (C) Semi-quantitative reverse transcription polymerase chain reaction analysis of collagen II, aggrecan, MMP-13 and TIMP-1 mRNA expression. Values are expressed as the mean \pm standard deviation $(\mathrm{n}=5)$. ${ }^{\mathrm{P}}<0.05$ vs. Sham group; ${ }^{*} \mathrm{P}<0.05$ vs. model group. NPC, nucleus pulposus cell; ECM, extracellular matrix; MMP, matrix metalloproteinase; TIMP, tissue inhibitor of MMPs.

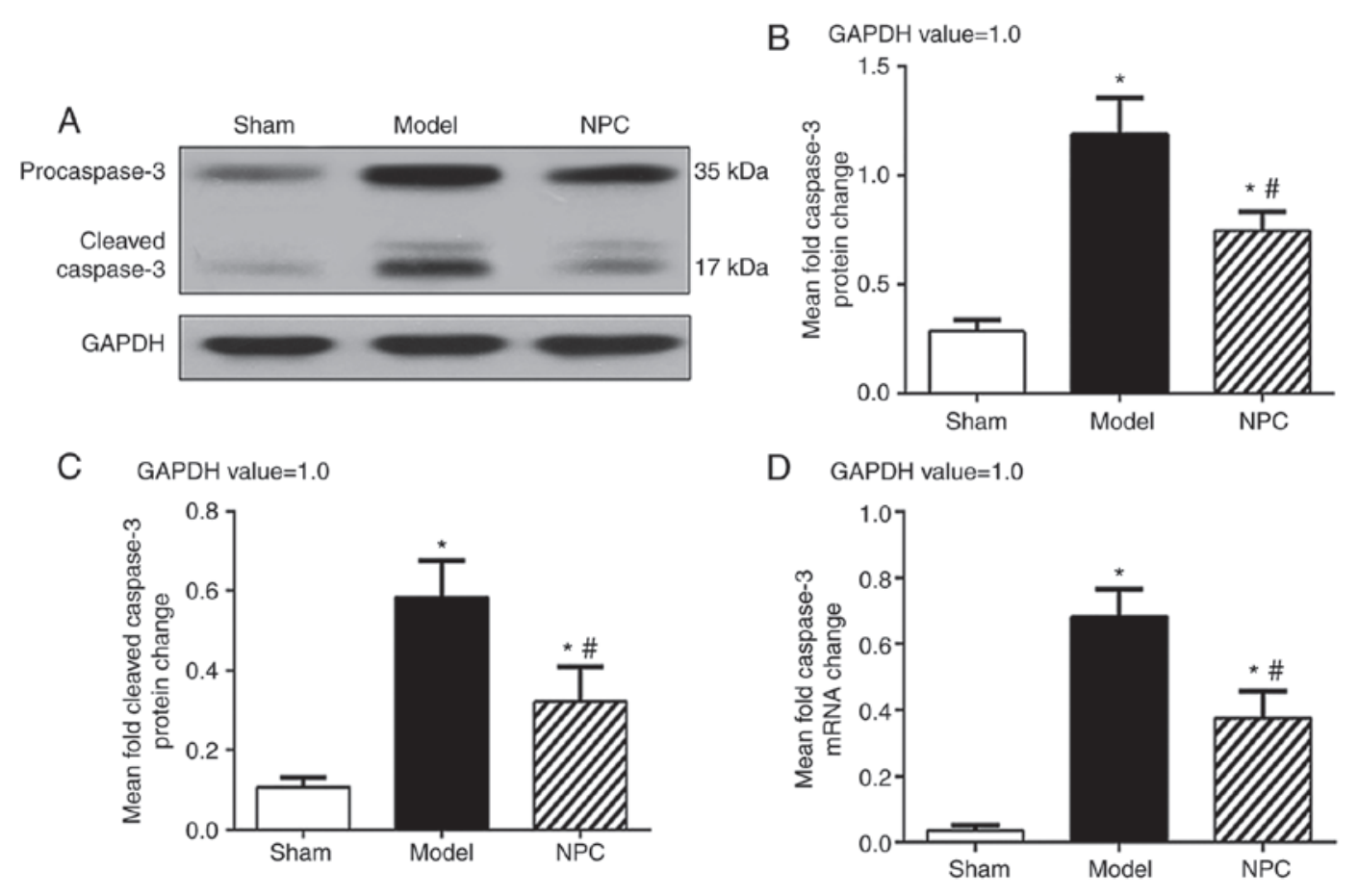

Figure 6. NPCs decreased the protein and mRNA expression levels and activation of caspase-3. (A-C) Western blot analysis of caspase-3 protein expression and caspase activation in endplate cartilage tissue. (D) Semi-quantitative reverse transcription polymerase chain reaction analysis for quantification of caspase- 3 mRNA expression. Values are expressed as the mean \pm standard deviation $(n=6)$. ${ }^{*} \mathrm{P}<0.05$ vs. Sham group; " $\mathrm{P}<0.05$ vs. Model group. NPCs, nucleus pulposus cells.

group were significantly increased compared with those in the model group $(\mathrm{P}<0.05)$. NPC treatment therefore inhibited the DDD-associated decreases in the mRNA and protein levels of collagen II and aggrecan. MMP-13 mRNA and protein expression levels were significantly increased, while TIMP-1 mRNA and protein expression levels were significantly decreased in the model group compared with those in the Sham group $(\mathrm{P}<0.05)$. Compared with the model group, the 
A GAPDH value $=1.0$

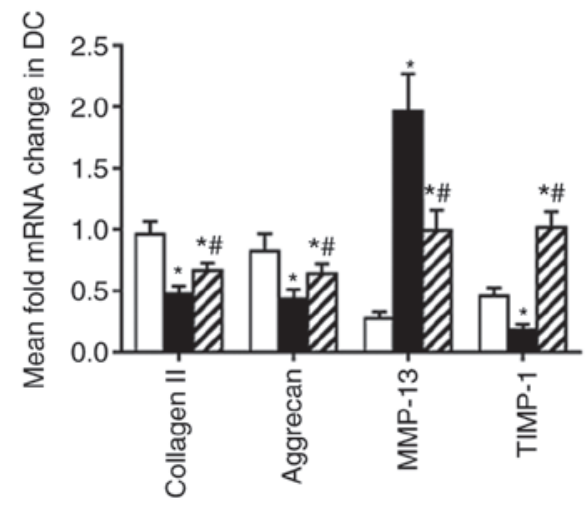

B GAPDH value $=1.0$

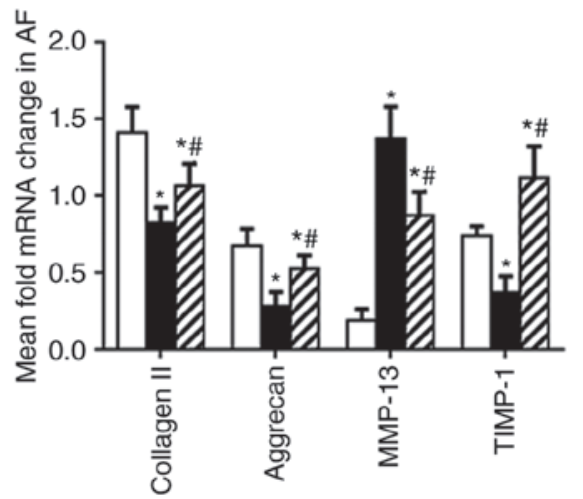

$\square$ Blank

- Control

ש Experiment

Figure 7. NPCs increased the expression of collagen II, aggrecan and TIMP-1 and suppressed the expression of caspase-3 and MMP-13 in (A) DCs and (B) AFCs stimulated by IL-1 $\beta$. Values are expressed as the mean \pm standard deviation. ${ }^{*} \mathrm{P}<0.05$ vs. Blank group; ${ }^{*} \mathrm{P}<0.05$ vs. Control group ( $\mathrm{n}=5$ ). Groups: Blank, DCs or AFCs cultured for $24 \mathrm{~h}$; Control and experimental groups, DCs or AFCs stimulated with or without IL-1 $\beta$ ( $20 \mathrm{ng} / \mathrm{ml}) 24 \mathrm{~h}$, respectively, followed by co-culture with NPCs in a Transwell insert for $24 \mathrm{~h}$. NPCs, nucleus pulposus cells; TIMP, tissue inhibitor of MMPs; MMP, matrix metalloproteinase; DCs, disk chondrocytes; AFCs, annulus fibrosus cells; IL, interleukin.

NPC group exhibited a significant decrease in MMP-13 levels and a significant increase in TIMP-1 levels $(\mathrm{P}<0.05)$, further suggesting a beneficial effect of NPC transplantation in DDD.

NPCs prevent DDD-induced apoptosis in vivo. To examine the effect of allogenic NPC transplatation on apoptosis, the protein expression and activation (Fig. 6A-C) and mRNA levels (Fig. 6D) of apoptosis-associated caspase-3 was detected in endplate cartilage tissue. The results demonstrated that total and cleaved caspase-3 protein, as well as mRNA expression in the model group was significantly increased compared with that in the Sham group $(\mathrm{P}<0.05)$, while NPC transplantation was able to significantly decrease the expression of apoptosis-associated caspase-3 protein and mRNA as well as the activation of caspase 3 protein $(\mathrm{P}<0.05)$.

NPCs regulate the expression of ECM in vitro. The expression of collagen II, aggrecan, MMP-13 and TIMP-1 in DCs and AFCs was determined by using semi-quantitative RT-PCR. DCs and AFCs were stimulated by IL-1 $\beta$ (20 ng/ml) for $24 \mathrm{~h}$ under serum-free to successfully generate an in vitro model of cell injury. Compared with the Blank group, the Control and Experimental groups demonstrated significantly increased mRNA expression of MMP-13 $(\mathrm{P}<0.05)$ and significantly decreased mRNA expression of collagen II, aggrecan and TIMP-1 $(\mathrm{P}<0.05)$. Compared with the Control group, the Experimental group had significantly increased collagen II, aggrecan and TIMP-1 expression levels $(\mathrm{P}<0.05)$, while the content of MMP-13 was significantly decreased $(\mathrm{P}<0.05)$. These results indicated that co-culture of NPCs with DCs and AFCs significantly enhanced the ability of DCs and AFCs to secrete ECM (Fig. 7).

NPC decreases apoptosis of DCs and AFCs stimulated by $I L-1 \beta$ in vitro. The expression of caspase- 3 mRNA in DCs and AFCs was detected by semi-quantitative RT-PCR (Fig. 8A). The apoptotic rate of DCs and AFCs (based on early apoptosis + late apoptosis) was determined by flow cytometry (Fig. 8B). The results indicated that co-culture of NPCs with IL-induced DCs and AFCs significantly reduced the apoptotic rate and caspase-3 expression of DCs and AFCs stimulated by IL-1 $\beta(\mathrm{P}<0.05)$.

The migration of NPCs is increased by DCs and AFCs. The results of the present study indicated that DCs and AFCs promoted NPC migration under co-culture conditions, and this ability was significantly enhanced by damaged DCs and AFCs (Fig. 9A and B). Polycarbonate inserts (pore size, $8.0 \mu \mathrm{m}$ ) were used to establish a migration model in a Transwell co-culture system. The migration of NPCs was observed following $12 \mathrm{~h}$ of co-culture with DCs and AFCs. In the co-culture system, DCs and AFCs significantly increased the migration of NPCs; after DCs and AFCs were stimulated by IL-1 $\beta$, the migration of NPCs was significantly enhanced $(\mathrm{P}<0.05$; Fig. 9C). The migration of NPCs was markedly upregulated when co-cultured with DCs and AFCs.

\section{Discussion}

Lumbar disc degeneration-associated lower back pain is an important health issue that has a significant impact on society and economy (23). The currently available clinical therapies involve symptomatic relief of pain by administering medications or physiotherapy (24). Despite the high cost and potential complications $(19,25)$, the rate of the surgical interference increased 2.4-fold between 1998 and 2008, and the cost per case more than tripled during this period (26). In addition, the rate of revision spinal surgery has had an increasing trend, and the initial surgeries had a failure rate of $15-40 \%$ (27). Treatment of DDD is a clinical challenge, and the NP, AF and DCs are rarely regenerative. Cell transplantation is a novel therapy based on the supplementation of matrix-producing cells. A limited number of studies are available on NPC transplantation. Nishimura and Mochida (8) studied the positive effect of percutaneous reinsertion of fresh or cryopreserved NP in rats. However, Okuma et al (9) reported that the reinsertion of stimulated NPCs delayed IVD degeneration. NPCs were also used to build 3D tissue engineering complexes to repair IVD (28). Ganey et al (18) demonstrated that DC transplantation was a viable treatment for degenerated or damaged 
A GAPDH value $=1.0$
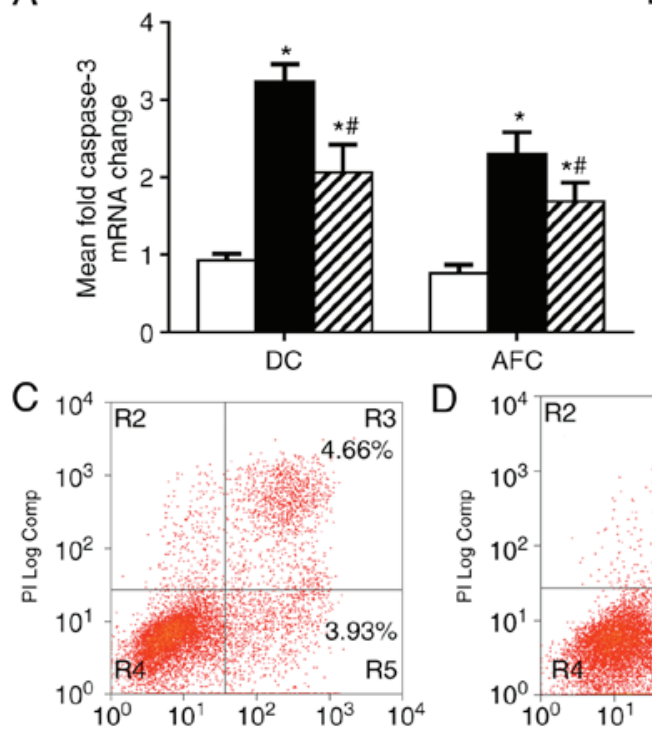

$\mathrm{F}$

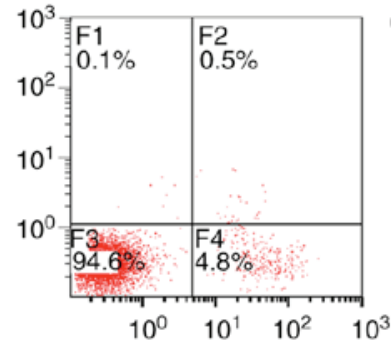

B

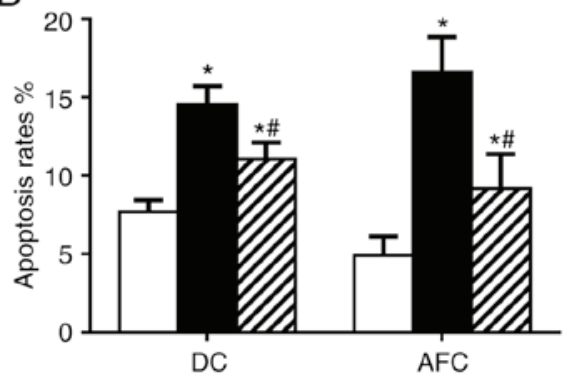

E
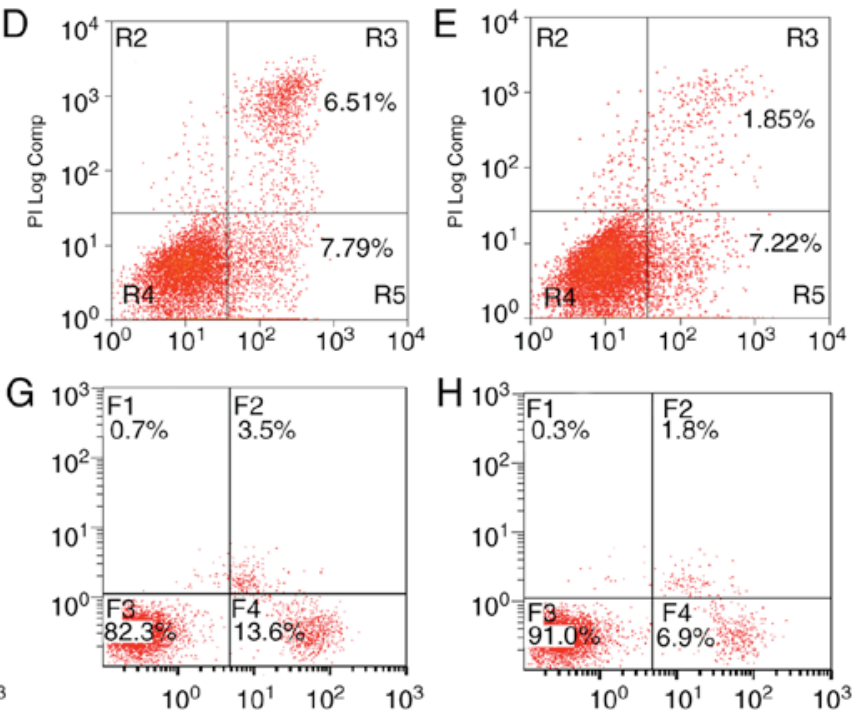

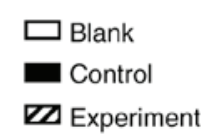

ZZ Experiment

Figure 8. NPCs suppress the expression of caspase-3 and apoptosis in DCs and AFCs stimulated by IL-1 $\beta$. (A) mRNA content of caspase-3 measured by semiquantitative reverse transcription polymerase chain reaction. (B) Apoptotic rates in the Blank, Control and Experiment groups determined by flow cytometry. Apoptotic rates in (C) Blank (D) Control and (E) Experimental group of DCs measured by flow cytometry. Apoptotic rates in (F) Blank, (G) Control and (H) Experimental group of AFCs measured by flow cytometry. Values are expressed as the mean \pm standard deviation $(\mathrm{n}=5)$. ${ }^{*} \mathrm{P}<0.05$ vs. Blank group; ${ }^{*} \mathrm{P}<0.05$ vs. control group. Groups: Blank, DCs or AFCs cultured for $24 \mathrm{~h}$; Control and experimental groups, DCs or AFCs stimulated with or without IL-1 $\beta$ (20 ng/ml) $24 \mathrm{~h}$, respectively, followed by co-culture with NPCs in a Transwell insert for $24 \mathrm{~h}$. NPCs, nucleus pulposus cells; DCs, disk chondrocytes; AFCs, annulus fibrosus cells; IL, interleukin.
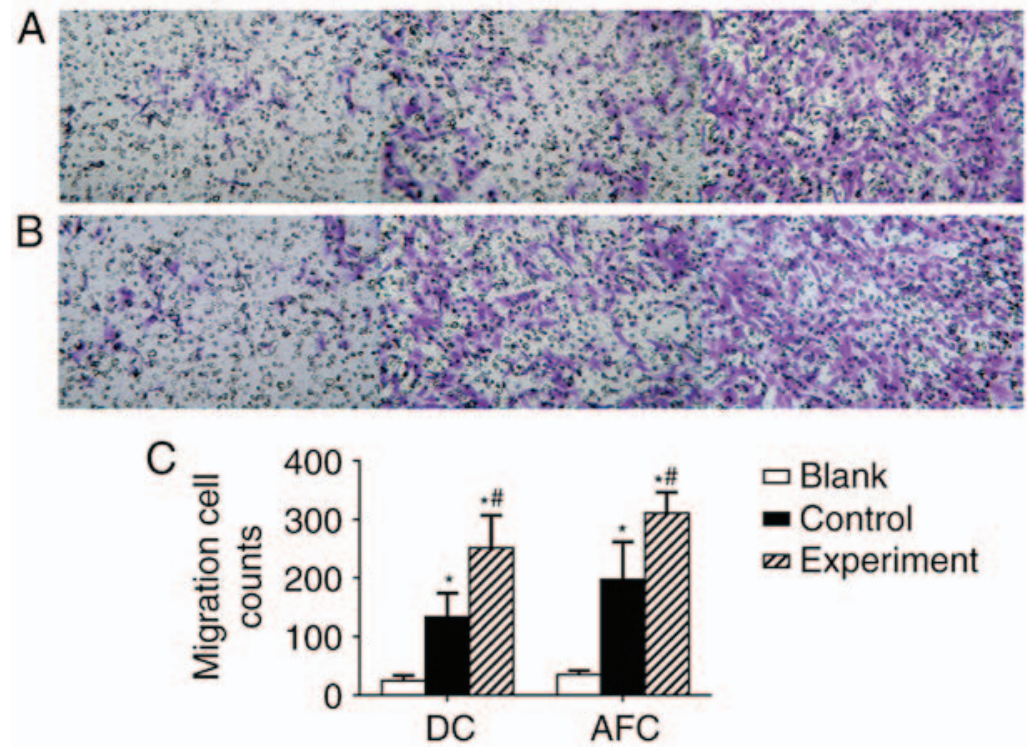

Figure 9. NPC migration was enhanced by co-culture with DCs and AFCs. Representative images of migrated NPCs co-cultured with (A) DCs and (B) AFCs. Panels 1, 2 and 3 depict the Sham, Control and Experimental groups, respectively ( $0.1 \%$ crystal violet staining; magnification, x 200). (C) Quantified numbers of migrated cells in a microscopic field of view (magnification, $\mathrm{x} 200)$. Values are expressed as the mean \pm standard deviation $(\mathrm{n}=5)$. ${ }^{*} \mathrm{P}<0.05 \mathrm{vs}$. Blank group; "P<0.05 vs. control group. Groups: Blank, NPCs allowed to migrate in a Transwell insert for $12 \mathrm{~h}$; Control and Experimental groups, NPCs as in the blank group, with DCs or AFCs that had been stimulated with or without IL-1 $\beta(20 \mathrm{ng} / \mathrm{ml})$ for $24 \mathrm{~h}$ in the lower well. NPCs, nucleus pulposus cells; DCs, chondrocytes; AFCs, annulus fibrosus cells. 
IVD. However, only few studies have assessed the mechanism of action of NPCs in the treatment of disc degeneration. The objective of the present study was to evaluate the mechanisms via which NPCs attenuate DDD in vivo and in vitro. It provided the first evidence, to the best of our knowledge, that NPCs are able inhibit IVD apoptosis and that damaged DCs and AFCs enhance the migratory capacity of NPCs.

The present study used a rat model of needle insertion-induced DDD to evaluate the effect of NPC transplantation in inhibiting disc degeneration and apoptosis in vivo. Radiography demonstrated that NPC transplantation partially restored disc height, consistent with the results of Feng et al (29). Histological evidence demonstrated that allogenic NPCs remained viable for as long as 4 weeks following transplantation. The transplanted NPCs regulated the metabolism of ECM by inhibiting degradation and increasing the content of aggrecan and collagen II in endplate cartilage. The reason that endplate cartilage was selected to assess ECM-associated mRNA and protein expression was that NP and AF tissues, including the transplanted NPCs, may exhibit experimental variability; however, endplate cartilage was easy to extract and relatively stable, and was able to represent the degree of disc degeneration. It was also identified that the transplanted NPCs were mainly localized in the transition zone, and certain cells migrated into the inner AF, thus suggesting that NPCs may have the ability to migrate in the discs. In addition, the in vitro experiments demonstrated that NPCs had the ability to migrate to DCs and AFCs, and this migration ability was enhanced following induction of the DCs and AFCs by IL-1 $\beta$ in vitro. In vivo, the transplanted NPCs located in the inner AF exhibited a spindle-like shape similar to that of native AFCs, while NPCs within the NP presented with a more rounded shape similar to that of native NPCs. These results provided morphological evidence that the transplanted NPCs underwent differentiation. There is not much difference between NPCs and inner AFCs regarding the cell phenotype, and thus far, there is no morphological assay to distinguish between these two cells types. The present study attempted to identify transplanted NPCs that differentiated into AFCs by using immunofluorescence analysis of collagen II and aggrecan, but there was little difference between these two cells types. Thus, an accurate method to differentiate between NPCs and inner AFCs is required. The indication that NPCs are able to 'home' to AF and differentiate into AFCs, may be of value toward the improved understanding of the nature of NPCs and provide a novel theoretical basis for the treatment of DDD.

However, a number of difficulties remain regarding the clinical applications of cell therapy. Due to the lack of blood vessels, cell injection into IVDs may be the only way for transplantation at present. The cell survival rate remains low and the cell status remains poor in IVD cell transplantation. Various studies indicated that the IVD was hyperosmolar when compared with other tissues. The reported values varied from 430 to $496 \mathrm{mOsm}$, which are higher than those in other tissues $(30,31)$, with unpredictable changes in $\mathrm{pH}$ or inflammatory factors. Thus, the transplanted cells were indeed affected (32). Given the unique microenvironment inside the IVD, NPCs from this tissue type may be the best candidates for transplantation.
Cell leakage is another problem. Vadala et al (33) raised the concern that mesenchymal stem cells may migrate out of the nucleus, causing undesirable bone formation. Fields et al (34) reported that fibrous ring cracks may occur in the majority of patients, and such cracks were not detectable by magnetic resonance imaging. The prolonged existence of such cracks may increase the risk of cell leakage, thus limiting the clinical application of cell transplantation. Currently, there are a number of methods to prevent transplanted cell leakage by using biological carriers, including microsphere scaffolds and scaffolds with sustained induction of cytokines and enhanced expression of their phenotype (35). In addition, fibrin glue may also be used to prevent cell leakage (36).

Another problem is that a needle is required to pass through the AF into the NP in cell transplantation. Carragee et al (37) reported that the IVD degeneration rate was significantly accelerated in patients undergoing discography so that the integrity of the IVD structure may be damaged, although whether such a procedure will accelerate the degeneration requires further verification. Given the current problems in the treatment of IVD degeneration, NPCs were used as seed cells in this experiment by using a 33-gauge insulin microinjector to inject cells into each disc within at least $5 \mathrm{~min}$. A needle as small as possible should be used to reduce the risk of procedure-associated disc degeneration; however, the injection time should be as long as possible to reduce the possibility of cell leakage that may cause associated complications.

The in vitro experiments of the present study demonstrated that co-culture of NPCs with DCs or AFCs increased the ECM composition and inhibited the apoptosis of damaged DCs and AFCs. NPCs increased the ECM composition by inhibiting the expression of MMP-13 and promoting the expression of TIMP-1 in DCs and AFCs. The ECM is mainly composed of a fibrillar collagen network that offers tensile strength and an aggregation of proteoglycan that resists compressive forces (38). Abnormal stress alters the ECM of the disc (39). In addition, endplate calcification affects the metabolism of the ECM (40). Aberrations in MMP-13 best reflect the metabolic changes of collagen in the cartilaginous matrix (41), which lead to the degradation of collagen I/II and aggrecan. TIMP-1 is the most important factor to regulate tissue MMP activity (42). In the present study, NPCs co-cultured with DCs and AFCs demonstrated significantly increased collagen II and aggrecan expression. Further studies have identified that NPCs regulated the expression of MMP13/TIMP-1 in impaired DCs and AFCs. Using flow cytometry, it was observed that NPC co-culture inhibited apoptosis of AFCs and DCs. A previous study demonstrated that disc aging and degeneration were accompanied by a decreased number of cells in the disc, a change attributable to necrosis and apoptosis (43). Apoptosis is an important factor for IVD degeneration. Inhibition of apoptosis may be a way to treat lumbar IVD degeneration (44). The present study demonstrated that NPCs decreased apoptosis by inhibiting the expression of caspase-3 in impaired DCs and AFCs.

The in vivo experiment of the present study demonstrated that transplanted allogenic NPCs migrated into the inner AF. An in vitro experiment further confirmed that migration of NPCs is affected by the surrounding environment, and that NPCs tended to migrate to the damaged site. A further observation of the in vitro study was that DCs and AFCs promoted 
NPC migration, while the in vitro Transwell assay suggested that damaged DCs and AFCs significantly increased NPC migration. Therefore, it was hypothesized that NPCs possess the ability to migrate in the IVD under physiological conditions. When degeneration, including endplate cartilage damage or NP rupture, occurs in the disc, chemokines are released, which induce the migration of NPCs to the damaged site, where they work together with DCs or AFCs at the damaged site to repair the local injury and inhibit disc degeneration. With the aggravation of degeneration, NPCs themselves undergo apoptosis and become dysfunctional, which decreases their ability to migrate, resulting in irreversible IVD degeneration. Improving the number and activity of NPCs may be valuable in developing strategies for repairing IVD degeneration.

Although the results of the present study support the feasibility of using NPC therapy for the treatment of IVD degeneration, future study is required. The present study focused on the introduction of NPCs in a reproducible rat model of IVD degeneration in vivo as well as in vitro. Future studies may determine whether NPCs transplanted into the degenerating disc are able to differentiate and migrate, which may aid in the elucidation of the nature and extent of the contribution of NPCs to disc repair and regeneration.

\section{Competing interests}

The authors declare that they have no competing interests.

\section{References}

1. Ylinen J: Physical exercises and functional rehabilitation for the management of chronic neck pain. Eura Medicophys 43: 119-132, 2007.

2. Salomon JA, Vos T, Hogan DR, Gagnon M, Naghavi M, Mokdad A, Begum N, Shah R, Karyana M, Kosen S, et al: Common values in assessing health outcomes from disease and injury: Disability weights measurement study for the Global Burden of disease study 2010. Lancet 380: 2129-2143, 2012.

3. Raj PP: Intervertebral disc: Anatomy-physiology-pathophysio logytreatment. Pain Pract 8: 18-44, 2008.

4. Levin DA, Hale JJ and Bendo JA: Adjacent segment degeneration following spinal fusion for degenerative disc disease. Bull NYU Hosp Jt Dis 65: 29-36, 2007.

5. Buckwalter JA: Aging and degeneration of the human intervertebral disc. Spine 20: 1307-1314, 1995.

6. Lipson SJ and Muir H: 1980 Volvo award in basic science. Proteoglycans in experimental intervertebral disc degeneration. Spine 6: 194-210, 1981.

7. Kim KW, Lim TH, Kim JG, Jeong ST, Masuda K and An HS: The origin of chondrocytes in the nucleus pulposus and histologic findings associated with the transition of a notochordal nucleus pulposus to a fibrocartilaginous nucleus pulposus in intact rabbit intervertebral discs. Spine 28: 982-990, 2003.

8. Nishimura $\mathrm{K}$ and Mochida J: Percutaneous reinsertion of the nucleus pulposus. An experimental study. Spine 23: 1531-1539, 1998.

9. Okuma M, Mochida J, Nishimura K, Sakabe K and Seiki K: Reinsertion of stimulated nucleus pulposus cells retards intervertebral disc degeneration: An in vitro and in vivo experimental study. J Orthop Res 18: 988-997, 2000.

10. Cao C, Zou J, Liu X, Shapiro A, Moral M, Luo Z, Shi Q, Liu J, Yang $\mathrm{H}$ and Ebraheim N: Bone marrow mesenchymal stem cells slow intervertebral disc degeneration through the NF-kappaB pathway. Spine J 15: 530-538, 2015.

11. Sakai D, Mochida J, Iwashina T, Hiyama A, Omi H, Imai M, Nakai T, Ando K and Hotta T: Regenerative effects of transplanting mesenchymal stem cells embedded in atelocollagen to the degenerated intervertebral disc. Biomaterials 27: 335-345, 2006.
12. Murrell W, Sanford E, Anderberg L, Cavanagh B and Mackay-Sim A: Olfactory stem cells can be induced to express chondrogenic phenotype in a rat intervertebral disc injury model. Spine J 9: 585-594, 2009.

13. Sivakamasundari V and Lufkin T: Stemming the degeneration: IVD stem cells and stem cell regenerative therapy for degenerative disc disease. Adv Stem Cells 2013: pii: 724547, 2013.

14. Risbud MV, Guttapalli A, Tsai TT, Lee JY, Danielson KG, Vaccaro AR, Albert TJ, Gazit Z, Gazit D and Shapiro IM: Evidence for skeletal progenitor cells in the degenerate human intervertebral disc. Spine 32: 2537-2544, 2007.

15. Blanco JF, Graciani IF, Sanchez-Guijo FM, Muntión S, Hernandez-Campo P, Santamaria C, Carrancio S, Barbado MV, Cruz G, Gutierrez-Cosío S, et al: Isolation and characterization of mesenchymal stromal cells from human degenerated nucleus pulposus: Comparison with bone marrow mesenchymal stromal cells from the same subjects. Spine 35: 2259-2265, 2010.

16. Hughes PC and Tanner JM: The assessment of skeletal maturity in the growing rat. J Anat 106: 371-402, 1970.

17. Kraus P and Lufkin T: Bovine annulus fibrosus cell lines isolated from intervertebral discs. Genom Data 10: 83-84, 2016.

18. Ganey T, Libera J, Moos V, Alasevic O, Fritsch KG, Meisel HJ and Hutton WC: Disc chondrocyte transplantation in a canine model: A treatment for degenerated or damaged intervertebral disc. Spine 28: 2609-2620, 2003

19. Lin Y, Li F, Chen W, Zeng H, Chen A and Xiong W: Single-level lumbar pyogenic spondylodiscitis treated with mini-open anterior debridement and fusion in combination with posterior percutaneous fixation via a modified anterior lumbar interbody fusion approach. J Neurosurg Spine 23: 747-753, 2015.

20. Pfirrmann CW, Metzdorf A, Zanetti M, Hodler J and Boos N: Magnetic resonance classification of lumbar intervertebral disc degeneration. Spine 26: 1873-1878, 2001.

21. Murrell W, Féron F, Wetzig A, Cameron N, Splatt K, Bellette B, Bianco J, Perry C, Lee G and Mackay-Sim A: Multipotent stem cells from adult olfactory mucosa. Dev Dyn 233: 496-515, 2005.

22. Livak KJ and Schmittgen TD: Analysis of relative gene expression data using real-time quantitative PCR and the $2^{-\Delta \Delta C_{\mathrm{T}}}$ method. Methods 25: 402-408, 2001.

23. Stanton TR, Latimer J, Maher CG and Hancock M: Definitions of recurrence of an episode of low back pain: A systematic review. Spine 34: E316-E322, 2009.

24. Chou R and Huffman LH; American Pain Society; American College of Physicians: Medications for acute and chronic low back pain: A review of the evidence for an American Pain Society/American College of Physicians clinical practice guideline. Ann Intern Med 147: 505-514, 2007.

25. Kwon B and Kim DH: Lateral lumbar interbody fusion: Indications, outcomes, and complications. J Am Acad Orthop Surg 24: 96-105, 2016.

26. Rajaee SS, Bae HW, Kanim LE and Delamarter RB: Spinal fusion in the United States: Analysis of trends from 1998 to 2008. Spine 37: 67-76, 2012.

27. Rajaee SS, Kanim LE and Bae HW: National trends in revision spinal fusion in the USA: Patient characteristics and complications. Bone Joint J 96-B: 807-816, 2014.

28. Stich S, Stolk M, Girod PP, Thomé C, Sittinger M, Ringe J, Seifert $M$ and Hegewald AA: Regenerative and immunogenic characteristics of cultured nucleus pulposus cells from human cervical intervertebral discs. PLoS One 10: e0126954, 2015.

29. Feng G, Zhao X, Liu H, Zhang H, Chen X, Shi R, Liu X, Zhao X, Zhang W and Wang B: Transplantation of mesenchymal stem cells and nucleus pulposus cells in a degenerative disc model in rabbits: A comparison of 2 cell types as potential candidates for disc regeneration. J Neurosurg Spine 14: 322-329, 2011.

30. Ishihara H, Warensjo K, Roberts S and Urban JP: Proteoglycan synthesis in the intervertebral disk nucleus: The role of extracellular osmolality. Am J Physiol 272: C1499-C1506, 1997.

31. van Dijk B, Potier E and Ito K: Culturing bovine nucleus pulposus explants by balancing medium osmolarity. Tissue Eng Part C Methods 17: 1089-1096, 2011.

32. Wuertz K, Godburn K, Neidlinger-Wilke C, Urban J and Iatridis JC: Behavior of mesenchymal stem cells in the chemical microenvironment of the intervertebral disc. Spine 33: 1843-1849, 2008. 
33. Vadalà G, Sowa G, Hubert M, Gilbertson LG, Denaro V and Kang JD: Mesenchymal stem cells injection in degenerated intervertebral disc: Cell leakage may induce osteophyte formation. J Tissue Eng Regen Med 6: 348-355, 2012.

34. Fields AJ, Liebenberg EC and Lotz JC: Innervation of pathologies in the lumbar vertebral end plate and intervertebral disc. Spine J 14: 513-521, 2014.

35. Liang CZ, Li H, Tao YQ, Peng LH, Gao JQ, Wu JJ, Li FC, Hua JM and Chen QX: Dual release of dexamethasone and TGF-beta3 from polymeric microspheres for stem cell matrix accumulation in a rat disc degeneration model. Acta Biomater 9: 9423-9433, 2013.

36. Chik TK, Ma XY, Choy TH, Li YY, Diao HJ, Teng WK, Han SJ, Cheung KM and Chan BP: Photochemically crosslinked collagen annulus plug: A potential solution solving the leakage problem of cell-based therapies for disc degeneration. Acta Biomater 9: 8128-8139, 2013

37. Carragee EJ, Don AS, Hurwitz EL, Cuellar JM, Carrino JA and Herzog R: 2009 ISSLS Prize Winner: Does discography cause accelerated progression of degeneration changes in the lumbar disc: A ten-year matched cohort study. Spine 34: 2338-2345, 2009.

38. Schmidt MB, Mow VC, Chun LE and Eyre DR: Effects of proteoglycan extraction on the tensile behavior of articular cartilage. J Orthop Res 8: 353-363, 1990.

39. Lotz JC, Colliou OK, Chin JR, Duncan NA and Liebenberg E: Compression-induced degeneration of the intervertebral disc: An in vivo mouse model and finite-element study. Spine 23: 2493-2506, 1998.
40. Holm S, Holm AK, Ekström L, Karladani A and Hansson T: Experimental disc degeneration due to endplate injury. J Spinal Disord Tech 17: 64-71, 2004.

41. Mitchell PG, Magna HA, Reeves LM, Lopresti-Morrow LL, Yocum SA, Rosner PJ, Geoghegan KF and Hambor JE: Cloning, expression, and type II collagenolytic activity of matrix metalloproteinase-13 from human osteoarthritic cartilage. J Clin Invest 97: 761-768, 1996.

42. Matrisian LM: Metalloproteinases and their inhibitors in matrix remodeling. Trends Genet 6: 121-125, 1990.

43. Gruber HE, Johnson TL, Leslie K, Ingram JA, Martin D, Hoelscher G, Banks D, Phieffer L, Coldham G and Hanley EN Jr: Autologous intervertebral disc cell implantation: A model using Psammomys obesus, the sand rat. Spine 27: 1626-1633, 2002.

44. Jiang W, Zhang X, Hao J, Shen J, Fang J, Dong W, Wang D, Zhang X, Shui W, Luo Y, et al: SIRT1 protects against apoptosis by promoting autophagy in degenerative human disc nucleus pulposus cells. Sci Rep 4: 7456, 2014.

This work is licensed under a Creative Commons Attribution-NonCommercial-NoDerivatives 4.0 International (CC BY-NC-ND 4.0) License. 